Correction

\title{
Publisher's Note - Overlapping Pagination Error
}

\section{Shu-Kun Lin}

Molecular Diversity Preservation International (MDPI), Kandererstrasse 25, CH-4057 Basel, Switzerland; E-mail: lin@mdpi.org

Published: 3 August 2006

Publisher's Note added on 3 August 2006: There is an overlapping pagination error. The paper "Int. J. Mol. Sci. 2006, 7, 131-154" is republished as "Int. J. Mol. Sci. 2006, 7, 231-254. Pages 144-154 are thus taken as blank pages. We apologize for this error and for any inconvenience.

(C) 2009 by the authors; licensee Molecular Diversity Preservation International, Basel, Switzerland. This article is an open-access article distributed under the terms and conditions of the Creative Commons Attribution license (http://creativecommons.org/licenses/by/3.0/). 